\title{
Market structure and the link between migration and trade
}

\author{
Silvio H. T. Tai
}

\begin{abstract}
Many recent studies have looked at the impact of international migration on trade and found a significant effect. They posit that migration fosters trade by lowering costs or by means of a preference bias. However, to my knowledge, market structure has not as yet been considered. Using data from Switzerland, this paper empirically assesses the extent to which migration affects trade, taking goods differentiation into account. A monopolistic model with a multisector economy (Chaney in Am Econ Rev 98(41):1707-1721, 2008) is then empirically estimated. The findings show that market structure explains the different channels through which migration affects trade.
\end{abstract}

Keywords Migration - International trade $\cdot$ Market structure $\cdot$ Gravity

JEL classification $\mathrm{F} 10 \cdot \mathrm{F} 22$

\section{Introduction}

The link between migration and trade has been well established by recent literature. An immigrant can act as an intermediary for information, preferences and networks. These trade-impacting migration mechanisms ${ }^{1}$ are generally presented to explain empirical findings. Yet the mechanisms themselves have not yet been identified empirically.

\footnotetext{
1 See Rauch (2001) for a survey of these mechanisms.
} 
This paper addresses the question of how migration affects trade and sheds some light on the mechanisms of preferences and costs. It is an empirical assessment underpinned by a model of firm heterogeneity in a multisector economy developed by Chaney (2008). The impact of migration can be studied in greater detail by considering the role of market structure with sector asymmetry throughout and each sector's level of product variety differentiation. Preferences and cost effects are then analyzed.

The literature endeavors to identify these mechanisms by treating a country's exports and imports differently. Basically, it is posited that the network effect impacts on both exports and imports by lowering costs, and that the preference effect has an impact solely on imports due to immigrant consumption. This would imply that migration has a greater effect on imports. However, Sect. 2 shows that Gould (1994) and Girma and Yu (2002) find migration has a greater effect on exports while Head and Ries (1998) and Wagner et al. (2002) find that migration has a greater impact on imports. Whereas the first set of papers studies a small sample made up largely of rich trade partners, the second set considers all the partners. This could suggest that, when the entire spectrum of traded products is considered, migration has a greater impact on imports.

The main contribution of this paper is to consider market characteristics by level of product differentiation. In the monopolistic competition framework adopted, the market can reflect all sorts of situations from monopoly to perfect competition with trade barrier effects differentiated. Any estimation of the migration effect is distorted if these differences are overlooked. For instance, take a country that exports highly differentiated products and imports homogeneous ones. Let us say this country exports watches and imports cocoa. So if immigration impacts more on imports than exports, the direct conclusion of a stronger effect of immigrants' preferences in the host country could be inaccurate. Maybe, in this case, the impact on imports is greater solely because they are structurally made up of products more likely to be affected by migration. My findings show that the product composition explains the different immigration effects.

Another contribution is the use of the migratory mirror flow, i.e. data on Swiss abroad. This kind of data is not readily available, but provides a definitive verification of migration effects. For example, consider a migration effect on Swiss imports introduced by foreigners in Switzerland. The corresponding effect should be found for Swiss people abroad on Swiss exports. In other words, if we assume that immigrants always raise preferences for the home country, Swiss emigrants should increase Switzerland's exports more than its imports.

It is common practice to study migration and trade focusing on just one country to prevent measurement errors. Although the data used are reliable (bearing in mind that each country counts immigrants in its own way), two distortions are created. First, the composition of exports and imports can be different. Rich countries specialize in the production of more highly differentiated goods, so their exports are more concentrated in differentiated products than their imports. Conversely, the countries studied in the literature are those that attract migration because of their high level of development. This is the second distortion, since the opposite flow of nationals abroad is overlooked. For example, the studies consider 
solely immigrants in the United States or the United Kingdom but not the opposite flow of American and British people abroad. These two distortions converge to create a bias in the comparison of the impact of migration on exports (of differentiated products) with the impact of immigrants on imports (of homogeneous products). My findings show that market structure has to be considered before any comparison can be made.

This paper focuses on Switzerland, using data from France to make some checks on endogeneity. Switzerland, to my knowledge, has never been studied for this kind of research. This is quite surprising given the high proportion of foreigners and its geographical position in the heart of Europe. Trade-migration effects have been studied for the United States (Gould 1994; Dunlevy and Hutchinson 1999), Canada (Head and Ries 1998; Wagner et al. 2002), and the United Kingdom (Girma and $\mathrm{Yu}$ 2002). Switzerland has a smaller surface area and greater population density than the United States and Canada (30 inhab/ $\mathrm{km}^{2}$ for the United States, 3 inhab $/ \mathrm{km}^{2}$ for Canada and 177 inhab $/ \mathrm{km}^{2}$ for Switzerland ${ }^{2}$ ), so one would expect to find more social interaction in the country boosting the business network and cultural transmission. An immigrant in Geneva is more likely to interact with another in Zurich than an immigrant in New York with another in Texas. These proportional distances are roughly equivalent for the two countries relatively speaking given their sizes, but correspond in absolute terms to about 290 and 2,290 km, respectively. However, like Switzerland, the United Kingdom also has a high population density. Yet the greater mobility of European Union nationals ${ }^{3}$ could well distort migration statistics on EU nationals in the United Kingdom. This is not the case for Switzerland thus far (and definitely not in the period studied from 1995 to 2000).

The repercussions of migration have become an issue with the steady increase in migration in recent decades. In Switzerland, the number of foreigners has been on the rise since the Second World War, despite a slight adjustment following the 1973 oil crisis. Switzerland wanted to attract immigrants in the early years following WWII, the situation changed after the 1960s when the country started to adopt more restrictive immigration policies. ${ }^{4}$ Despite migration barriers, the foreign population has grown more sharply than the Swiss population to the astonishing level of $20 \%$ of the country's population in recent years. New immigrants accounted for $62 \%$ of the net population increase from 1980 to 2000.

This paper is structured as follows. Section 2 looks at the relevant empirical literature. Section 3 presents the theoretical model and specification and Sect. 4 details the data. Section 5 reports on the findings and Sect. 6 presents the conclusion.

\footnotetext{
2 Source: United Nations Demographic and Social Statistics http://unstats.un.org/unsd/demographic/ products/dyb/DYB2002/Table03.pdf.

3 http://ec.europa.eu/youreurope/nav/fr/citizens/working/free-circulation/index.html.

4 See Melo et al. (2002), Sect. 3 for an overview of Switzerland's immigration policy.
} 


\section{Relevant literature}

\subsection{Review: the effect of migration on trade}

The literature has been most consistent in its demonstration of robust, tradeenhancing migration effects.

Gould (1994) is commonly cited as the pioneering study of the empirical relationship between migration and trade. He studies this link using American trade data from 1970 to 1986. Gould (1994) considers two basic mechanisms for this relationship. First, immigrants bring a preference for home-country products, which would imply an increase in imports in the host country. Second, immigrants bring foreign market information and contacts with the potential to lower transaction costs (e.g. by benefiting from the spread of the immigrant language in the host country, taking advantage of immigrant information on home varieties and preferences, and acting as go-betweens to strengthen otherwise unsound trade contracts). Gould (1994) studies the determinants of American trade with 47 countries, most of them (25) ranked as "high-income economies". The restrictive nature of the sample could well distort certain findings since the market structure of trade is biased towards the USA's richest partners. Moreover, its main specification is most particular in that Gould (1994) regressed the log of trade on $\beta(\mathrm{IMMI} /(\theta+\mathrm{IMMI}))$ (where $\beta$ and $\theta$ are estimated coefficients and IMMI is the number of immigrants) and posited that migration always has a stronger impact on exports than on imports. Nevertheless, he applies the usual log specification in the sensitivity analysis, finding that imports have a coefficient of 0.439 whereas exports have a coefficient of 0.176 .

Girma and Yu (2002) also consider a small sample of countries. They study the United Kingdom's trade with 48 countries from 1981 to 1993, considering the same two mechanisms as above. Like Gould (1994), 22 of the 48 partners are ranked "high-income economies". They find that migration has a greater impact on exports than on imports. These findings confirm a robust trade-enhancing migration effect. However, also like Gould, the study contains a high proportion of the UK's richest partners, which could well bias the findings and prompt at least a partial interpretation of the relationship between migration and trade.

Looking at a larger sample of countries, Head and Ries (1998) study the determinants of Canadian trade with 136 countries over the 1980-1992 period. The authors also consider preference, superior knowledge and preferential access to market opportunities as mechanisms underlying the impact of migration on trade. Their findings contradict Gould (1994) and Girma and Yu (2002). Interestingly, the broader range of countries reduces the potential bias observed in the studies presented above. They find that migration has a greater impact on imports than on exports.

\footnotetext{
5 In keeping with the 2006 World Bank classification in which 53 countries are ranked as low-income economies (GNI per capita of $\$ 905$ or less), 96 countries as middle-income economies (GNI per capita of $\$ 906$ to $\$ 11,115$ ) and 60 countries as high-income economies (GNI per capita of $\$ 11,116$ or more). Source: http://web.worldbank.org.
} 
Wagner et al. (2002) agree with Head and Ries that migration has a greater effect on imports than on exports. They look at provincial Canadian trade data (five provinces) with 160 countries from 1992 to 1995 . This approach is very interesting, since the fixed country effects do not coincide with the fixed trade-pair effect, since each trade pair corresponds to a Canadian province and a foreign country duo.

The last two papers suggest that, when the sample of countries is representative enough, migration can be found to have a larger effect on imports than on exports. This finding is significant and can be interpreted as: over and above preference effects, when a complete market structure composition is considered, imports cover a configuration of goods such that their trade is more likely to be affected by migration. Since none of these studies looks at market structure, their findings could reflect a distortion introduced by the difference in market structure between exports and imports.

Rauch and Trindade (2002) address this subject from a different angle. They estimate the effect of Chinese networks around the world based on the probability of finding a Chinese immigrant in the population of each country. In addition, they make a distinction between differentiated and homogeneous goods. The paper studies the trade of 63 countries in 1980 and 1990. The findings show that migration has a stronger effect on differentiated products.

\subsection{Are these mechanisms consistent?}

The causal effect of migration on trade is well founded. Nevertheless, the identification of the channels through which migration affects trade flows and the differences between the impact of migration on exports and imports are not very clear.

The preference mechanism is based entirely on immigrant consumption of homecountry products. The first problem with this definition is the extremely small scale of this personal consumption compared with the corporate operations involved in cost reductions. Head and Ries (1998) ${ }^{6}$ find that each immigrant generates $\$ 8,000$ in imports and $\$ 3,000$ in exports. This would mean that each immigrant in Canada consumes an astounding $(8,000-3,000) / 12=\$ 417$ per month in home-country products, due purely to their home-country preferences, and that immigrants consume almost twice as much as firms in trade. An asymmetric network effect could be considered to explain this difference, for example, a larger impact of networks on imports. However, Wagner et al. (2002, p. 511) consider a symmetric effect:

One mechanism applies only to imports, not exports. Immigrants may prefer certain goods from their country of origin, based on tastes developed before migration. These preferences would generate more imports from the country of origin.

Head and Ries' and Duvenly and Hutchinson's results imply that the preference effect is approximately double the information/enforcement effect

\footnotetext{
${ }^{6}$ Head and Ries (1998) present the most significant difference of the effect of migration on exports and imports (they are statistically different at the $95 \%$ level).
} 
( since the immigration effect on imports is approximately three times the effect on exports).

The second problem with this definition of preferences is that it disregards cultural transmission. This oversight could create some sizeable misrepresentations, since cultural transmission reaches a much broader range of people. Immigrant consumption is quantitatively limited to the number of immigrants, while cultural spread can potentially reach the entire community in the host country.

The third problem is the unidirectional limitation of this concept of preference, due to the immigrant consumption assumption (applied solely in the direction of host country to home country). Nonetheless, the simple matching of immigrants with host country reveals an immigrant's choice. This option is obviously determined by economic factors and circumstances, but affinity between countries should not be overlooked. Moreover, cultural traits are diffused in two directions: immigrants bring customs and values from the home country to the host country, but also from the host country to the home country. Bowles (1998) considers migration as an instrument of exposure to culture via different populations.

While previous studies have considered a narrow concept of preferences, I incorporate the notions above into a theoretical model of trade. Basically, the main difference in the model is the flexibility of the preference term, which is allowed to work bilaterally. Nevertheless, confirmation of this "two-way" characteristic of preferences is an econometric issue.

\section{Theoretical model and specification}

\subsection{Trade model}

This empirical study is underpinned by a monopolistic competition model with firm heterogeneity and a multisector economy. The mechanisms via which migration affects trade imply a reduction in trade costs and an increase in preferences, which vary according to the market structure. Hence the model needs to distinguish sectorbased differences, trade costs and preferences. One way to take into account these sector-based differences is to include a fixed export cost with firm heterogeneity by sector. This allows for extensive and intensive margins of trade whose impact varies with the extent of product substitutability. Consequently, fixed and variable costs are separated out to paint a clearer picture of the migration network's impact on costs.

Chaney (2008) develops a model with all these characteristics save the preferences term. I describe this model briefly and add a simple term $a_{i j}$ for preferences between countries. This procedure is in keeping with Combes et al. (2005), where a weight is introduced in order to describe bilateral preferences between countries. This term means that preferences can be captured in both directions, from the immigrant's home country to host country and vice versa. ${ }^{7}$ The model is outlined below.

\footnotetext{
${ }^{7}$ See Sect. 2 for a justification.
} 
The model considers a utility function with CES preferences. There are $H+1$ sectors with sector-specific elasticities of substitution $\sigma_{h}$. $H$ represents the number of differentiated sectors and the homogeneous good is the numeraire. Considering that each sector has $\Omega_{h}$ varieties and that a consumer consumes $q_{0}$ units of good 0 and $q_{h}(\omega)$ units of each variety $\omega$ of good $h$, utility is expressed as:

$$
U \equiv q_{o}^{\mu_{0}} \prod_{h=1}^{H}\left(\int_{\Omega_{h}}\left(a_{i j} q_{h}(\omega)\right)^{\frac{\sigma_{h}-1}{\sigma_{h}}} d \omega\right)^{\frac{\sigma_{h}}{\sigma_{h}-1} \mu_{h}}
$$

with $\mu_{0}+\sum_{h=1}^{H} \mu_{h}=1$ and $\sigma_{h}>1$.

Firm productivity $\phi$ in each sector follows a Pareto distribution $d G_{h}(\phi)=$ $\gamma_{h} \phi^{-\gamma_{h}-1}$ with cumulative distribution $G_{h}(\phi)=1-\phi^{-\gamma_{h}}$ and $\gamma>\sigma-1$. The cost of producing $q$ units and selling them in country $j$ is:

$$
c_{i j}^{h}(\phi)=\frac{w_{i} \tau_{i j}^{h}}{\phi} q+f_{i j}^{h}
$$

where $w_{i}$ is the wage.

A demand Eq. 3 can be derived from the utility function considering $Y_{j}$ as the sum of income in country $j$ with the dividends from firms from $j$ located worldwide.

$$
x_{i j}^{h}(\phi)=p_{i j}^{h}(\phi) q_{i j}^{h}(\phi)=\mu_{h} Y_{j}\left(\frac{p_{i j}^{h}(\phi)}{a_{i j} P_{j}^{h}}\right)^{1-\sigma_{h}}
$$

where $P_{j}^{h}$ is the price index in sector $h$ for country $j$ and $p_{i j}$ is the selling price.

Two trade barriers are considered in the model: a fixed export cost $f_{i j}^{h}$ and a variable cost in "iceberg" form $\tau_{i j}^{h}$. Separating out these two costs is useful to be able to introduce an effect of market structure on trade differentiated by firm heterogeneity. Moreover, this form makes for a more suitable consideration of the effect of migration on trade costs. Cost reduction mechanisms refer to the preferential access to market opportunities and the contacts an immigrant may have.

For productivity level $\phi$, the threshold can be determined from what a firm is able to export. The productivity cutoff is the zero profits level.

$$
\bar{\phi}_{i j h}=\lambda_{1}^{h}\left(\frac{f_{i j}}{Y_{j}}\right)^{\frac{1}{\sigma_{h}-1}} \frac{w_{i j} \tau_{i j}}{P_{j}}
$$

$\lambda_{1}^{h}$ is a constant by sector. It is described in Table 1 at the end of this section.

The price index is defined by $P_{j}^{1-\sigma}=\sum_{k=1}^{N} w_{k} L_{k} \int_{\bar{\phi}_{k j}}^{\infty}\left(\frac{\sigma_{h}}{\sigma_{h}-1} \times \frac{w_{k} \tau_{k j}}{\phi}\right)^{1-\sigma_{h}} d G(\phi)$, using the determined threshold:

$$
P_{j}^{h}=\lambda_{2}^{h} \times Y_{j}^{\frac{1}{\gamma^{h}}-\frac{1}{\sigma_{h}-1}} \times \theta_{j}^{h}
$$

with $\left(\theta_{j}^{h}\right)^{-\gamma_{h}} \equiv \sum_{k=1}^{N}\left(Y_{k} / Y\right) \times\left(w_{k} \tau_{k j}\right)^{-\gamma} \times f_{k j}^{-\left(\frac{\gamma}{\sigma-1}-1\right)}$.

$Y$ is world output, $L_{k}$ the labor income of country $k$ and $\lambda_{2}^{h}$ a constant by sector described in Table 1.

Demand Eq. 3 with this price index is written: 
Table 1 Model's constants by sector

$$
\begin{aligned}
& \lambda_{1}^{h}=\left(\frac{\sigma_{h}}{\mu_{h}}\right)^{\frac{1}{\sigma_{h}-1}}\left(\frac{\sigma_{h}}{\sigma_{h}-1}\right) \\
& \lambda_{2}^{h}=\left(\frac{\gamma_{h}-\left(\sigma_{h}-1\right)}{\gamma_{h}}\right)\left(\frac{\sigma_{h}}{\mu_{h}}\right)^{\frac{\gamma}{\sigma_{h}-1}-1}\left(\frac{\sigma_{h}}{\sigma_{h}-1}\right)^{\gamma}\left(\frac{1+\pi}{Y}\right) \\
& \lambda_{3}^{h}=\sigma_{h} \lambda_{4}^{1-\sigma_{4}} \\
& \lambda_{4}^{h}=\left(\frac{\sigma_{h}}{\mu_{h}} \times \frac{\gamma_{h}}{\gamma_{h}-\left(\sigma_{h}-1\right)} \times \frac{1}{1+\lambda_{5}^{h}}\right)^{\frac{1}{\gamma_{h}}} \\
& \lambda_{5}^{h}=\frac{\sum_{h=1}^{H} \frac{\left(\sigma_{h}-1\right) \mu_{h}}{\gamma_{h} \sigma_{h}}}{1-\sum_{h=1}^{H} \frac{\left(\frac{\left(h_{h}-1\right) \mu_{h}}{\gamma_{h} \sigma_{h}}\right.}{\sigma_{h}}} \\
& \lambda^{h}=\left(1+\lambda_{5}^{h}\right)+\mu_{h}
\end{aligned}
$$

$$
x_{i j}\left(\phi \mid \phi \geq \bar{\phi}_{i j}\right)=\lambda_{3}^{h} \times\left(\frac{Y_{j}}{Y}\right)^{\frac{\sigma_{h}-1}{\gamma_{h}}} \times a_{i j}^{\sigma_{h-1}} \times\left(\frac{\theta_{j}}{w_{i} \tau_{i j}}\right)^{\sigma_{h}-1} \times \phi^{\sigma_{h}-1}
$$

$\lambda_{3}^{h}$ is a constant by sector described in Table 1 at the end of this section. The aggregate exports are then obtained from the sum of all the firms' exports:

$$
X_{i j}^{h}=\mu_{h} \times \frac{Y_{i} Y_{j}}{Y} \times a_{i j}^{\sigma-1} \times\left(\frac{w_{i} \tau_{i j}^{h}}{\theta_{j}^{h}}\right)^{\gamma_{h}} \times\left(f_{i j}^{h}\right)^{-\left(\frac{\gamma_{h}}{\sigma_{h}-1}-1\right)}
$$

This model allows for a multisector estimation. Its findings are consequential in view of the hypothesis that migration increases product preferences and reduces trade costs. Identifying each sector by its elasticity of substitution, note, first, that the preference effect is magnified by elasticity. In other words, once a bilateral preference is defined, consumption will follow this preference so long as the consumers are not concerned about variety substitution. A good with $\sigma=1$ will not be affected by preferences, since the varieties are not substitutable in this case. Otherwise, a good with a high value of $\sigma$ will be easily influenced by preferences since its varieties are substitutable. The elasticity for preferences is:

$$
\frac{d \ln X_{i j}}{d \ln a_{i j}}=\sigma-1
$$

Second, an intensive margin is in operation, meaning that each exporter firm exports more when trade costs are reduced. This intensive margin is greater for sectors with a higher elasticity of substitution, which is the classic prediction made by Krugman (1980). Since competition is higher when products are more substitutable, a reduction in trade barriers prompts large differences in exports.

Third, with lower export costs, new and less productive firms start to export. Where $\sigma$ is low, traded products have a high degree of differentiation and firms are sheltered from competition, reaching large shares of the market. Conversely, where $\sigma$ is high, competition is high and low productivity is a serious disadvantage such that the firm can only reach a small share of the market. This is the extensive margin.

As Chaney shows, the effect of the extensive margin is greater than the effect of the intensive margin. The elasticity for variable costs $\tau_{i j}$ is 


$$
\frac{d \ln X_{i j}}{d \ln \tau_{i j}}=\underbrace{-(\sigma-1)}_{\text {intensive margin }}+\underbrace{((\sigma-1)-\gamma)}_{\text {extensive margin }}=-\gamma
$$

and for fixed costs $f_{i j}^{h}$ is

$$
\frac{d \ln X_{i j}}{d \ln f_{i j}}=\underbrace{0}_{\text {intensive margin }}+\underbrace{1-\frac{\gamma}{(\sigma-1)}}_{\text {extensive margin }}
$$

Hence the general (restricting) effect of trade costs on trade increases with $\sigma$, as opposed to preferences.

\subsection{Extension for migration}

The theoretical model used separates out fixed and variable trade costs. I assume that migration affects just fixed costs (and preferences). The literature considers two main channels through which migration could reduce costs: privileged information about markets and opportunities and contract reinforcement. Both of them represent a fixed cost to be overcome. The supplier-buyer matching process clearly represents a fixed cost incurred before any shipment is made. However, contract reinforcement is less clearly defined as a fixed cost. Confusion can arise since a weak contract can generate additional variable costs such as "debased metal, rotting fruits or stocking with runs" (Rauch and Trindade 2002, p. 117), but this is a consequence of the contract and not the cost of the contract. Business partnership contracts are nevertheless sealed before shipments are made and their cost should not normally depend on the volume to be traded.

As regards the total impact of migration on trade, Eq. 11 follows the trade model incorporating a multisector differentiation where each sector is identified by its elasticity of substitution. The degree of substitutability will define cost and preference behaviour.

$$
\frac{d \ln \operatorname{Trade}_{i j}}{d \operatorname{lnmig}_{i j}}=F(\sigma)
$$

The decomposition of migration's effect on trade in terms of costs and preferences is written:

$$
\frac{d \ln \left(\operatorname{Trade}_{i j}\right)}{d \ln \left(\operatorname{mig}_{i j}\right)}=\underbrace{\frac{\partial \ln \operatorname{Trade}_{i j}}{\partial \ln a_{i j}} \times \frac{\partial \ln a_{i j}}{\partial \operatorname{lnmig}}}_{\text {preference component }}+\underbrace{\frac{\partial \ln \operatorname{Trade}_{i j}}{\partial \ln f_{i j}} \times \frac{\partial \ln f_{i j}}{\partial \ln \operatorname{mig}_{i j}}}_{\text {fixed cost component }}
$$

In elasticity notation: $\tau_{a} \equiv \frac{\partial \ln \operatorname{Trade}_{i j}}{\partial \ln a_{i j}}, \alpha_{m} \equiv \frac{\partial \ln a_{i j}}{\partial \operatorname{lnmmig} i_{i j}}, \tau_{f} \equiv \frac{\partial \ln T \operatorname{Trade}_{i j}}{\partial \ln f_{i j}}$ and $\varphi_{m} \equiv \frac{\partial \ln f_{i j}}{\partial \operatorname{lnmmig} g_{i j}}$

$$
F(\sigma)=\tau_{a} \times \alpha_{m}+\tau_{f} \times \varphi_{m}
$$

The impact of migration on trade via the preference channel is determined by two elasticities: $\tau_{a}$ and $\alpha_{m}$ henceforth named preference (complementary) elasticities. These two elasticities have a positive sign since I assume that migration has a positive impact on preferences and preferences have a positive impact on trade. 
Conversely, the impact of migration on trade via the cost channel is determined by: $\tau_{f}$ and $\varphi_{m}$ henceforth named cost (complementary) elasticities. These two elasticities have a negative sign since I assume that migration has a negative impact on costs (reducing costs) and costs have a negative impact on trade (reducing trade). The product of both of them and then their resulting impact is nonetheless also positive.

Hence the impact of migration on trade is a linear combination of preference and cost components. Since one component reaches the maximum value when the other equals zero, a simple way of writing the linear combination is to weight $\beta$ to these maximum values, $\beta \in[0,1]$. Then $\beta=0$ when migration's entire effect on trade operates solely via the cost channel and $\beta=1$ when its entire effect operates solely via the preference channel. Equation 13 becomes:

$$
F(\sigma)=\beta \times\left(\tau_{a} \times \alpha_{m}\right)_{\max }+(1-\beta) \times\left(\tau_{f} \times \varphi_{m}\right)_{\max }
$$

Plugging Eqs. 8 and 10 into 14:

$$
F(\sigma)=\beta \times(\sigma-1) \times\left(\alpha_{m}\right)_{\max }+(1-\beta) \times\left(1-\frac{\gamma}{\sigma-1}\right) \times\left(\varphi_{m}\right)_{\max }
$$

and

$$
F(\sigma)=(\sigma-1) \times\left(\alpha_{m}\right)_{\max }=\left(1-\frac{\gamma}{\sigma-1}\right) \times\left(\varphi_{m}\right)_{\max }
$$

it follows that:

$$
\begin{gathered}
\alpha_{m}=\beta \times\left(\alpha_{m}\right)_{\max } \Rightarrow \alpha_{m}=\beta \times \frac{F(\sigma)}{\sigma-1} \\
\varphi_{m}=(1-\beta) \times\left(\varphi_{m}\right)_{\max } \Rightarrow \varphi_{m}=(1-\beta) \times \frac{F(\sigma)}{1-\frac{\gamma}{\sigma-1}}
\end{gathered}
$$

\subsection{Specification}

Trade function (7) is estimated using a gravity equation. The first specification considers an ordinary least squares (OLS) estimator with traditional control variables such as population, common border and common language. ${ }^{8}$ These control variables are important since migration could spuriously reflect trade channels established by colonial history or facilitated by a common language and adjacency. Dyadic variable preferences $\left(a_{i j t}\right)$, fixed costs $\left(f_{i j t}\right)$ and variable costs $\left(\tau_{i j}\right)$ are captured by:

$$
\begin{gathered}
a_{i j t}=\operatorname{mig}_{i j t}^{\beta D} \operatorname{dist}_{i j}^{E} \exp \left(A_{a} \text { clang }_{i j}+B_{a} \text { colony }_{i j}+C_{a} \operatorname{cbord}_{i j}\right) \\
f_{i j t}=\operatorname{mig}_{i j t}^{(1-\beta) D} \exp \left(A_{f} \text { lang }_{i j}+B_{f} \text { colony }_{i j}\right) \\
\tau_{i j}=\operatorname{dist}_{i j}^{E} \exp \left(A_{\tau} \operatorname{lang}_{i j}+B_{\tau} \text { colony }_{i j}+C_{\tau} \operatorname{cbord}_{i j}\right)
\end{gathered}
$$

\footnotetext{
${ }^{8}$ The colony variable does not apply to Switzerland.
} 
where $^{9}$ :

$X=(\sigma-1) X_{a}+\left(1-\frac{\gamma}{\sigma-1}\right) X_{f}+(\gamma) A_{\tau} \quad$ for $X=A$ and $B$

$Y=(\sigma-1) Y_{a}+(\gamma) C_{\tau} \quad$ for $Y=C$ and $E$

$D=\beta(\sigma-1)+(1-\beta)\left(1-\frac{\gamma}{\sigma-1}\right)$

Country-specific variables are captured by gross domestic product. Time fixed effects $\left(\mathrm{FE}_{\mathrm{t}}\right)$ are introduced to capture the overall variation in world trade and technology, concerning mainly transport and communication.

The estimated equation is then:

$$
\begin{aligned}
\ln X_{i j t}= & \lambda \ln \left(\operatorname{gdp}_{i t}\right)+\mu \ln \left(\operatorname{gdp}_{j t}\right)+v \ln (\mathrm{pop})_{i t} \\
& +\delta \ln \left(\operatorname{pop}_{j t}+A \operatorname{clang}_{i j}+B \text { colony }_{i j}\right. \\
& +C \operatorname{cbord}_{i j}+D \operatorname{lnmig}_{i j t}+E \ln d_{i j}+\mathrm{FE}_{t}+\varepsilon_{i j}
\end{aligned}
$$

Recent methodological progress has improved the estimation of gravity equations. ${ }^{10}$ Two main improvements are incorporated: omitted variables are captured by country-specific fixed effects and heteroskedasticity is corrected by a Poisson Pseudo Maximum Likelihood (PPML) estimator.

Country fixed effects are added in to capture omitted country-specific effects. This greatly reduces the risk of the migration variable capturing omitted variables.

Despite the popularity of the log-linear form of the gravity equation, it overlooks heteroskedasticity issues. In fact, the multiplicative form of the gravity equation provides a stochastic error term that, in its log-linear form, does not violate OLS homoskedasticity conditions solely under highly specific conditions. Santos Silva and Tenreyro (2006) propose an exponential form estimated by a PPML estimator to correct this problem.

Considering these two developments, the estimated equation becomes:

$$
\begin{aligned}
X_{i j t}= & \exp \left[\lambda \ln \left(\operatorname{gdp}_{i t}\right)+\mu \ln \left(\operatorname{gdp}_{j t}\right)+v \ln (\mathrm{pop})_{i t}+\delta \ln (\mathrm{pop})_{j t}\right. \\
& +A \operatorname{clang}_{i j}+B \text { colony }_{i j}+C \operatorname{cbord}_{i j}+D \operatorname{lnmig}_{i j t}+E \ln d_{i j} \\
& \left.+\mathrm{FE}_{t}+\mathrm{FE}_{i}+\mathrm{FE}_{j}+\varepsilon_{i j}\right]
\end{aligned}
$$

Standard errors are corrected for heteroskedasticity by White's (1980) method and clustered by country pairs to take into account the correlation of errors over the years.

\section{Data}

I use data mainly from Switzerland, although data from France are also used in a robustness check. In both cases, my data describe foreigners in the country (Switzerland or France) and nationals (Swiss or French) abroad.

\footnotetext{
9 For the sake of clarity, sector $h$ indices are omitted henceforth.

${ }^{10}$ For more details, see Anderson and van Wincoop (2003), Feenstra (2004), and Santos Silva and Tenreyro (2006).
} 
The use of migration stock instead of flows avoids the problem of endogeneity raised by reverse causality or even by a missing agent. Moreover, migration flows would disregard resident stock, which has an influence on current economic outcomes.

The Swiss Federal Statistics Office and the Swiss Federal Department of Foreign Affairs provided the data for Switzerland. The data for France come from a census ${ }^{11}$ and the French Ministry of Foreign and European Affairs. For the sake of data comparability, this paper uses data on the period from 1995 to 2000 with the exception of data on immigrants in France, where only 1999 data are used due to availability and compatibility problems.

The number of immigrants in Switzerland is measured in mid-year, while Swiss emigrants are counted at the end of the year. This is why the number of immigrants is analyzed with a six-month lag such that, for example, 2000 data (collected in June/July) are considered as 1999 data.

The trade data used in this article are taken from NBER, United Nations Trade Data (Feenstra et al. 2005). This database provides four-digit SITC data aggregated into three digits for matching with the elasticity of substitution database.

The elasticities of substitution are based on the United States elasticities estimated by Broda and Weinstein (2006) as proxies. Data on elasticities of substitution for each country are not available. Instead, the United States elasticities are used as proxies because of the country's representability in the world economy.

The sector-based trade data present some very high, broadly scattered elasticities. Figure 1 of Sect. 5 shows that just $6.3 \%$ of imports and $4.0 \%$ of exports have an elasticity higher than nine spread in a sigma interval from 9 to 33 . These data are ultimately not considered, ${ }^{12}$ as explained in Sect. 5 mainly because of their high dispersion and substantial potential for biasing the results.

Bilateral distances are calculated as the sum of the distances between the largest cities of both countries, weighted by the share of the population living in each city. Geographical variables such as common border (a dummy variable set to 1 for pairs of countries that share a border) and common language (dummies equal to one if both partners share a language) are extracted from the CEPII database. ${ }^{13}$

The data on gross domestic product and population are taken from the World Bank World Development Indicators.

\footnotetext{
11 Source: INSEE, National Institute for Statistics and Economic Studies, France.

12 A total of $10.1 \%$ of imports and $18 \%$ of exports were deleted from the sector-based analysis for other reasons. Some NBER trade data sectors do not match with the elasticities data: $3.8 \%$ of imports and $11.7 \%$ of exports. In the case of exports, one code (900) alone accounts for $7.8 \%$ of this $11.7 \%$. The authors of the trade database assume that the breakdown of Sect. 9 is essentially meaningless and reflects the reporting country's unwillingness to provide the product detail and, in some cases, partner detail as well. Therefore, these data are not included in the estimations.
}

13 http://www.cepii.fr/anglaisgraph/bdd/distances.htm. 


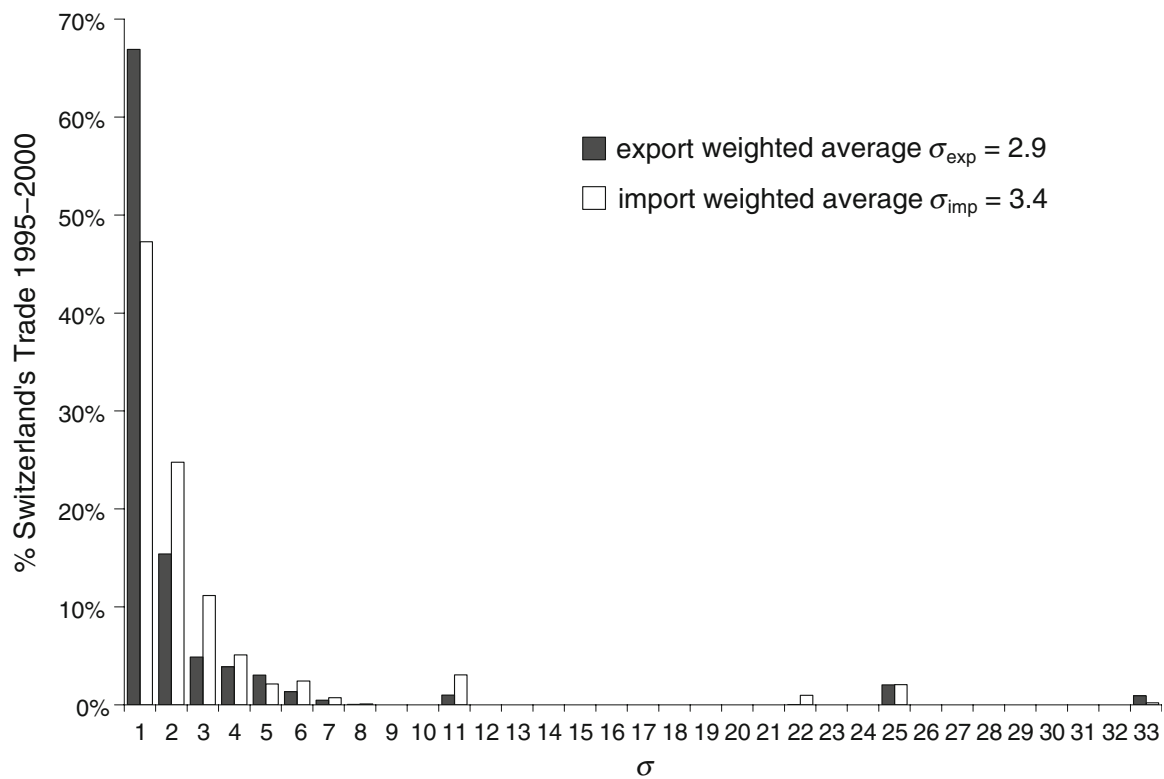

Fig. 1 Switzerland's sigma specialization. This graph calculates sector trade for each integer $\sigma$ (elasticity of substitution) from 1995 to 2000. This quantity is then divided by total trade. For example, the first bar is calculated as the sum of the trade of all sectors between $\sigma=1.00$ and $\sigma=1.99$ and this amount is then divided by total trade

\section{Findings}

\subsection{The impact of immigrants on Switzerland's aggregate trade}

Taking first a conventional approach, Table 2 reports the findings on the effect of immigrant stocks on Switzerland's aggregate exports and imports. Columns (1) and (2) show the results of the basic OLS gravity equation for Switzerland imports and exports, respectively. The gravitational determinants are more or less equivalent for both flows except for partner population and adjacency. For a given level of GDP, the partner population affects exports negatively and has no statistical effect on imports. Given that per capita GDP measures level of development, this fact implies that Switzerland exports more to countries with a higher level of development while this criterion is indifferent for imports. Adjacency affects Switzerland's imports only and does not influence exports. Common language does not have an impact on trade, probably due to the fact that Switzerland is a multilingual country. For example, a French-speaking region of Switzerland does not have a language advantage over a German-speaking country, although the "common language" dummy assumes it nonetheless. Yet the correlation between language and common border is 0.32 , which could justify a colinearity between these two variables. To sum up, Swiss products are consumed more by richer countries and the implications of a common border affect imports only. 


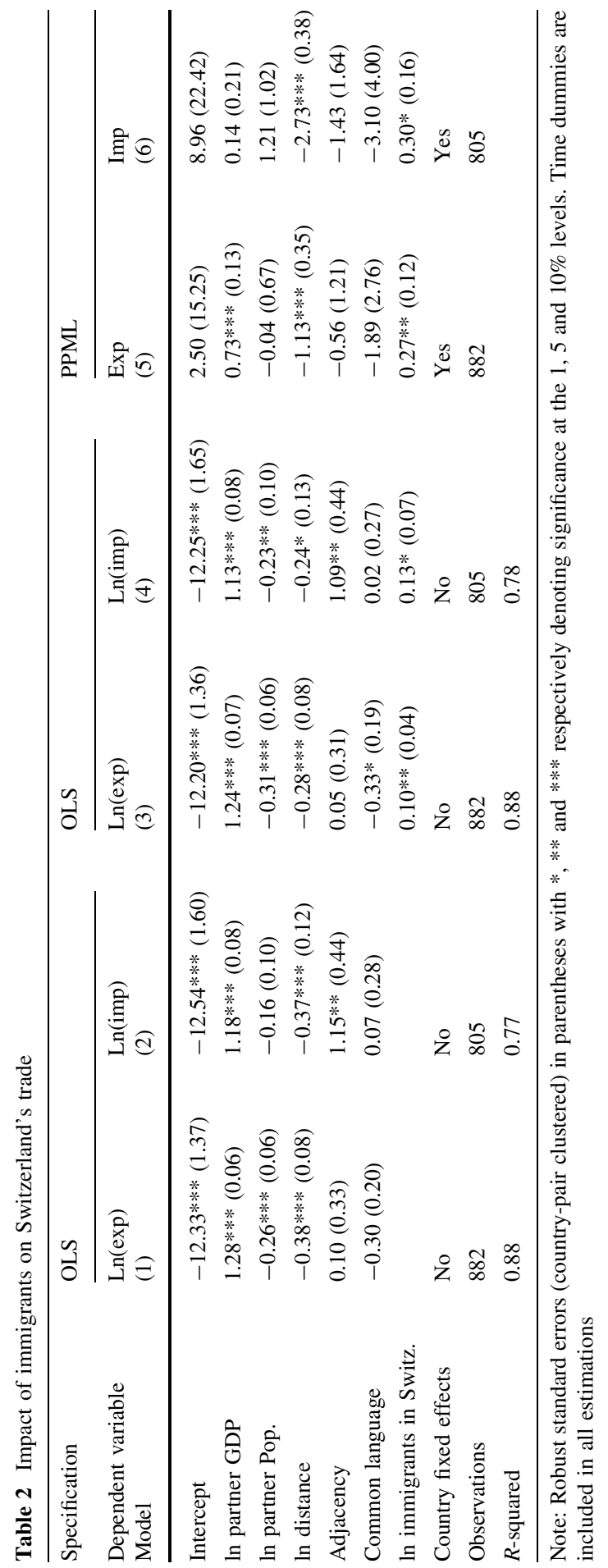


Regressions (3) and (4) introduce the logarithm of the stock of immigrants in Switzerland. The other variables have broadly the same effect on exports and imports, comparatively speaking. It is worth noting that the distance coefficient and its level of significance are smaller than in the previous regressions. Immigrant stocks seem to capture some information associated with distance. In this basic specification, immigrants have a greater influence on imports than on exports, even though this difference is not statistically significant. While this OLS estimator is appropriate for comparisons with other studies and provides a view of the gravitational determinants of Swiss trade, it is not the best specification for identifying the impact of immigrants in particular. The next specification takes into account omitted variables and heteroskedasticity issues.

Regressions (5) and (6) are estimated by a PPML and country fixed effects are included. Country fixed effects control for missing variables that could bias the migration coefficient, as explained in Sect. 3. Yet this methodology also controls for the dyadic dimension, since the trade concerns just one country. So all the dyadic variables such as distance and adjacency are colinear to these fixed effects and are not significant, even though they are included to ensure a complete control of the migration variable. The second upshot of this methodology is that it overcontrols for the impact of migration, resulting in underestimated coefficients for this variable. This disadvantage in terms of the coefficient's accuracy actually plays a positive role for its confidence, as applied by Gould (1994).

In regressions (5) and (6) we find a significant impact of immigrants on trade. A $10 \%$ increase in the stock of immigrants raises exports by $2.69 \%$ and imports by $3.03 \%$. This difference is not statistically significant, but it tends to confirm the findings made by Head and Ries (1998) and Wagner et al. (2002).

Yet the inclusion of fixed effects could raise a potential endogeneity issue given the variations in the migration variable over time (with dyadic fixed effects). This is a problem because the change in migration over time (basically the migration flows) may well tie in with the trade flows. I use two strategies to address this issue: an instrumental regression with twice-lagged migration stock (see Table 5 in the appendix) and the inclusion of French data (see Sect. 5.2). All checks confirm the results obtained in Table 2 .

These findings might imply that international flows of people create certain directional links between countries, links that would be more beneficial to trade flowing from home country to host country. This means, for example, that a Chinese immigrant in the United States would contribute more for US imports from China than for US exports. Since the network can take effect in both directions (although its effect can be asymmetric), this phenomenon would be conventionally explained by a preference for home-country product consumption.

\subsection{The impact of immigrants on Switzerland's disaggregated trade}

These migration mechanisms are fairly intuitive and have been developed by past studies. However, these analyses have overlooked the market structure of trade. Migration could affect exports and imports of different sectors in a systematically different way. Then, migration mechanisms could be distinguished only if the 
degree of trade flow substitutability were the same. One way of testing this assertion is to pool sector-based trade considering each sector as a good with differentiated varieties. Consequently, the interaction with the sector elasticity of substitution could verify the impact of the market structure.

Before proceeding to these estimations, it is worth analyzing the trade distribution of these sectors. Figure 1 shows the share of Swiss exports and imports by integer $\sigma$. The data for the values of $\sigma$ are provided by Broda and Weinstein (2006). The graph shows the distribution of Switzerland's trade on $\sigma$, and especially the concentration of exports in more differentiated products (low values of $\sigma$ ).

Turning now to the estimation of disaggregated sector-based export and import data from 1995 to 2000, the most reliable estimator (PPML) is used for this regression with the trade data being derived from Feenstra (2005). Elasticity-ofsubstitution statistics are not available for each country, so data on the United States are used as proxies. Broda and Weinstein (2006) estimate these elasticities for the period from 1990 to 2000.

This estimation corresponds to function (11). This function assumes a polynomial form:

$$
F(\sigma)=f_{0}+f_{1} \times \sigma+f_{2} \times \sigma^{2}+\cdots+f_{n} \times \sigma^{n}
$$

where $f_{0}, \ldots, f_{n}$ are migration terms of interaction.

A small number of interactions make for a more general estimator. A high value of $n$ customizes the estimation by incorporating part of the errors into the predictions. Alternatively, the first derivative of preference elasticity is always negative if $\sigma$ 's exponent is less than 2. This could be problematic because it could permanently induce a behaviour not predicted by the theoretical model. Squared $\sigma$ is then taken for the estimations. Higher powers were tested (results available upon request), but the results were not robust to the different databases used in this article. $^{14}$

The pooled estimation presents a very uneven distribution of data. Figure 1 clearly shows that most of the data $(95 \%)$ are concentrated in a narrow range from $\sigma=1$ to $\sigma=9$, while a residual amount of trade is spread in a large interval from $\sigma=9$ to $\sigma=33 .{ }^{15}$ Table 3 reports on the migration variable coefficients for the three samples: all data, $\sigma<9$, and $9<\sigma<33$. The estimator used is the PPML with all dummies and controls applied so far. Migration influences trade in the entire sample and the second sample. The coefficients and their degree of significance are similar. Data from the third sample are therefore not included in the following estimations.

Table 4 presents the results of the disaggregated sector data regressions for exports and imports. Migration is then interacted twice with $\sigma$ and $\sigma^{2}$. Columns (1) to (4) report on the findings for Switzerland, and columns (5) and (6) add data from

\footnotetext{
14 These databases are: Swiss people abroad, foreigners in France and French people abroad.

15 These outliers can considerably disrupt the findings. Since the estimates are made based on $\sigma$ 's interaction, the "leverage" of these points on $\sigma$ is high. Moreover, the spread is too diffuse: there are four points (counting by integer $\sigma$ ) in the interval from $\sigma=9$ to $\sigma=33$. No regression could be representative in this case.
} 
Table 3 Sector-pooled estimation: restricting the sample

\begin{tabular}{llll}
\hline Dependent variable & \multicolumn{2}{l}{ Exp and imp pooled } \\
\cline { 2 - 4 } $\begin{array}{l}\text { Sample } \\
\text { Model }\end{array}$ & $\begin{array}{l}\text { All Data } \\
(1)\end{array}$ & $\begin{array}{l}\sigma<9 \\
(2)\end{array}$ & $\begin{array}{l}\sigma>9 \\
(3)\end{array}$ \\
\hline ln Immigrants & $0.191^{* *}$ & $0.181^{* *}$ & 0.583 \\
ln Switzerland & $(0.091)$ & $(0.089)$ & $(0.410)$ \\
Observations & 74457 & 70735 & 3722 \\
Available trade $(\%)$ & $100 \%$ & $94.9 \%$ & $5.1 \%$ \\
\hline
\end{tabular}

Note: Robust standard errors (country-pair clustered) in parentheses with *, ** and *** respectively denoting significance at the 1,5 and $10 \%$ levels. Time and country dummies are included in all estimations. All models are estimated by PPML

France for an endogeneity check. The data on immigrants in France are available for 1999 only and on French people abroad for the period 1995-2000. The pooling of data on these two countries is useful because it tones down the effect of country fixed effects. These fixed effects could cause endogeneity because, in the presence of just one country, they also are dyadic fixed effects, which are colinear to the cross-sectional dimension of the migration variable. The results for the migration interacted terms are quite similar to those found in columns (1) to (4), suggesting that there is little endogeneity. This fact, combined with the results of the instrumental regression on Swiss immigration in Table 5 in the appendix, validates the estimated results obtained. This robustness also validates the functional form of $\mathrm{F}(\sigma)$ with terms to the power of 1 and $2 .^{16}$

Country and time fixed effects are applied and a dummy variable is included for imports in order to control for size difference effects for exports and imports. The results for Switzerland in columns (1)-(4) show, as expected, that the dyadic variables' coefficients are not significant. Columns (1) and (2) present the findings for exports and imports, respectively. The composition of trade of the sectors seems to determine the impact of migration similarly on imports and on exports. The interaction terms have a significant coefficient (at the 99\% level) and generate similar parabolas. Both point out that intermediate values of $\sigma$ (3.59 and 3.83) correspond to a maximum impact $(0.27$ and 0.28$)$. Above the asymmetry between imports and exports, migration impacts on trade depend largely on the sector. This could be verified by pooling together exports and imports into one regression. Such specification provides a robustness check for the effects of sector differentiation with a more complete distribution of trade on $\sigma$. The products of some sectors are only exported or imported, and then exports and imports present individually an incomplete range of sectors. Results presented in column (3) confirm previous results. These results can be expressed in elasticity notation as follows:

$$
F(\sigma)=\frac{\partial \ln (\text { Trade })}{\partial \ln (\text { Immig })}=0.178 \times \sigma-0.023 \times \sigma^{2}
$$

\footnotetext{
${ }^{16}$ A test to the power of 3 (not reported) failed this same test.
} 


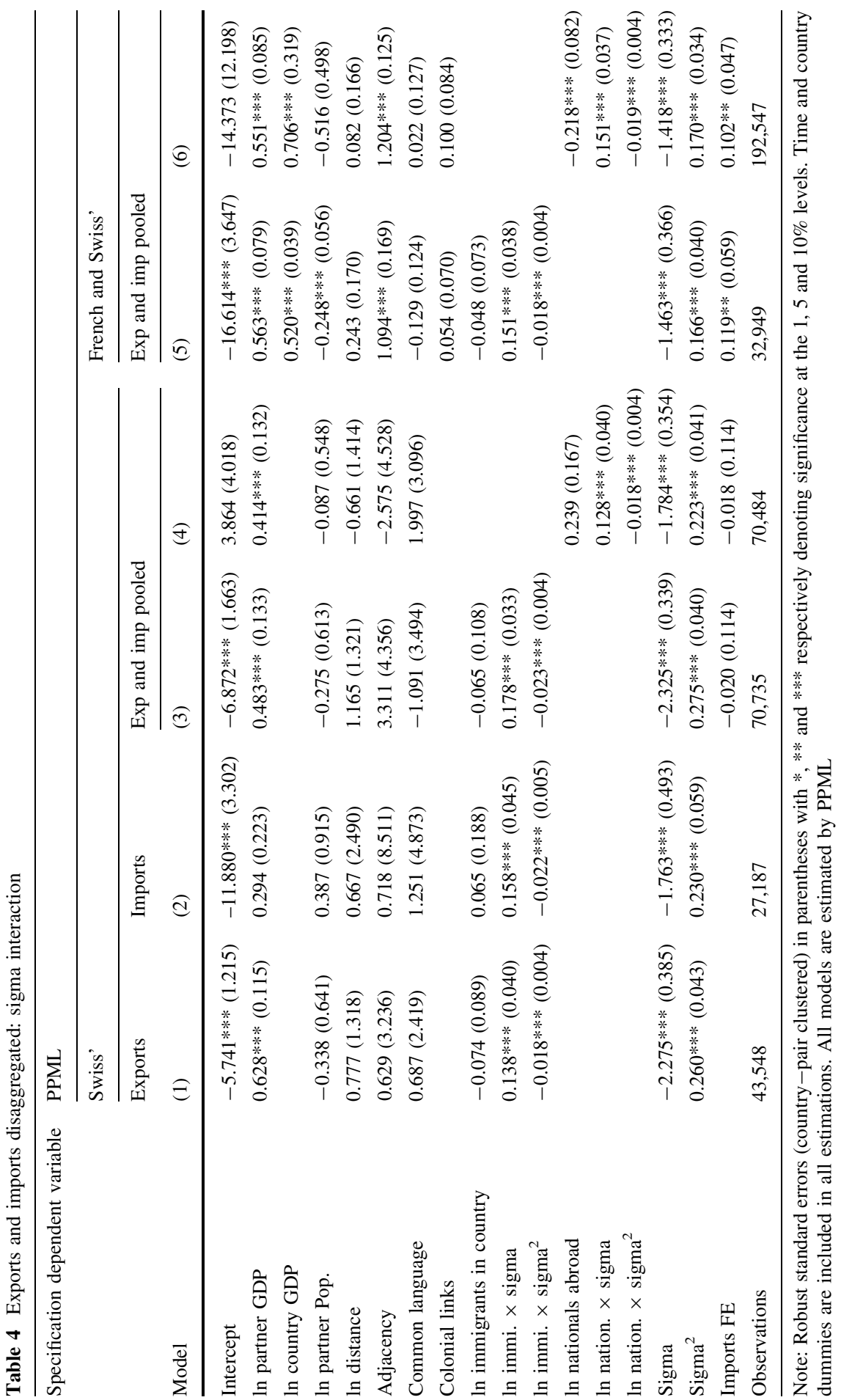


Therefore, $F(\sigma)$ has the same shape for the three specifications, indicating a robust relationship. A last test is conducted in column (4). Data on the Swiss abroad are used to estimate the effect of these emigrants on Switzerland's exports and imports. So far I have considered the immigration to Switzerland, which could select a kind of immigrant who looks for a higher level of development. Results confirm that the functional form of Eq. 21 holds independently of a possible idiosyncrasy bias of migrants.

\subsubsection{Disentangling migration effects}

Substituting $F(\sigma)$ in Eqs. 17 and 18, we obtain:

$$
\begin{aligned}
\alpha_{m} & =\beta \frac{0.178 \sigma-0.023 \sigma^{2}}{\sigma-1} \\
\varphi_{m} & =(1-\beta) \frac{0.178 \sigma-0.023 \sigma^{2}}{1-\frac{\gamma}{\sigma-1}}
\end{aligned}
$$

The relationship between migration and market structure is identified based on the theoretical model: $\tau_{a}=\sigma-1$ and $\tau_{f}=1-\frac{\gamma}{\sigma-1}$.

Maintaining $\gamma=9$ in order to respect the model's condition $\gamma>\sigma-1$, Fig. 2 charts the overall impact of migration on trade (top graph) and the partial effects of migration on trade by costs and preferences (bottom graph). Since $\beta$ is not estimated, this analysis applies $\beta=50 \%$, which simulates a situation where $50 \%$ of migration effects channel through costs and $50 \%$ through preferences. ${ }^{17}$

Some direct conclusions can be drawn from Fig. 2. First, the total elasticity of migration with respect to trade comes to a maximum of $0.17+0.17=0.34$, meaning that a $10 \%$ increase in the stock of immigrants raises trade by up to $3.4 \%$. Second, to disentangle the impacts, the direct effects of migration on preferences $\left(\alpha_{m}\right)$ and on costs $\left(\varphi_{m}\right)$ are very small compared to the subsequent effect of preferences on trade $\left(\tau_{a}\right)$ and the effect of costs on trade $\left(\tau_{f}\right)$. This is quite natural: preferences and costs can have a huge effect on trade while migration slightly biases preferences and costs. To quantify these effects, at the abovementioned peak level, a $10 \%$ change in preferences and costs prompts a $20 \%$ and $-15 \%$ change in trade, respectively. A $10 \%$ change in the stock of immigrants implies a $0.8 \%$ change in preferences and $-1.1 \%$ in costs.

In addition, this paper's theoretical model finds that the effect of preferences on trade $\left(\tau_{a}\right)$ increases with $\sigma$. This happens because homogeneous products are more easily replaceable for a given level of formed preferences. It is a substitutability effect. The model also finds that the impact of costs on trade $\left(\tau_{f}\right)$ decreases with $\sigma$ due to the extensive margin. The extensive margin predicts that a reduction in trade barriers enables new exporters of differentiated goods to reach larger shares of the market than new exporters of homogeneous goods. The impact of migration on preferences $\left(\alpha_{m}\right)$ then decreases with $\sigma$ while it affects costs $\left(\varphi_{m}\right)$ in an inverted Ushape. This shape is highly asymmetric and concentrated in high values of $\sigma$, with a maximum of $\sigma=6.1$ converging very quickly to zero.

\footnotetext{
17 Relative behaviour between complementary elasticities does not change for any value of $\beta$.
} 


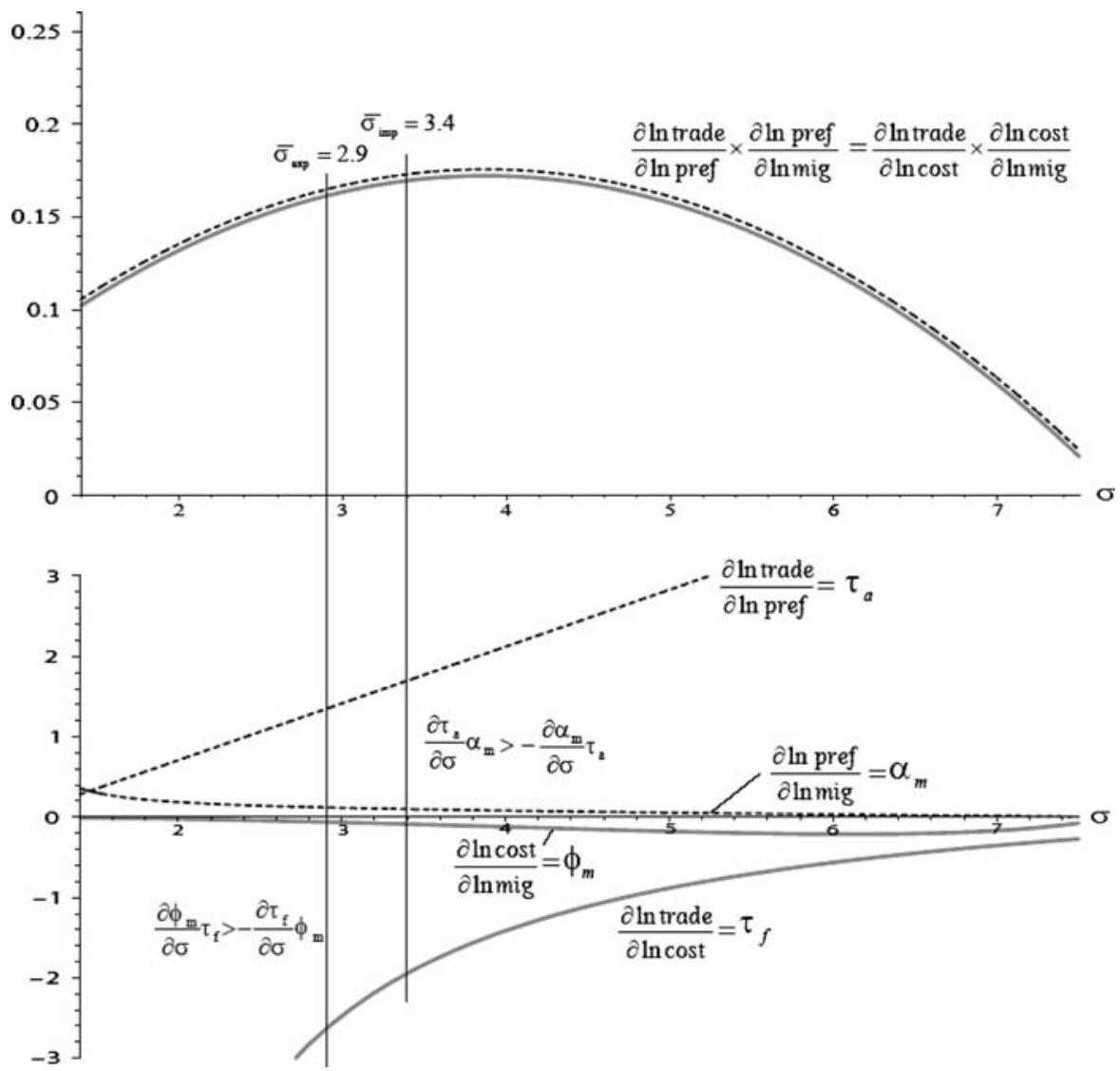

Fig. 2 The relationship between migration, costs and preferences

These findings imply that preferences are more affected by migration in differentiated sectors (with low elasticity of substitution). For example, a migrant might influence preferences for watches and clocks (sector 885 with $\sigma=1.34$ ) to a greater extent than cocoa (sector 072 with $\sigma=7.76$ ). It seems logical that migration should have a greater effect on preferences for differentiated products, since they can be more easily distinguished and identified by their nationality of origin. At the opposite extreme of the equation where $\sigma=+\infty$, migration has no effect on preferences since there is just one choice of variety that is constant across all the nationalities. The corresponding migration mechanisms in this case are the transmission of preferences such as cultural transmission and information transmission (about a new variety). Immigrant consumption of home-country products also has an influence, albeit lesser, on these preferences.

The second finding is that migration has an increasing impact on costs for more homogeneous goods up to a break point from where the impact of migration on costs diminishes quickly. These products may benefit from a trade channel established by migration, even if their trade is not sensitive to preferences. In this 


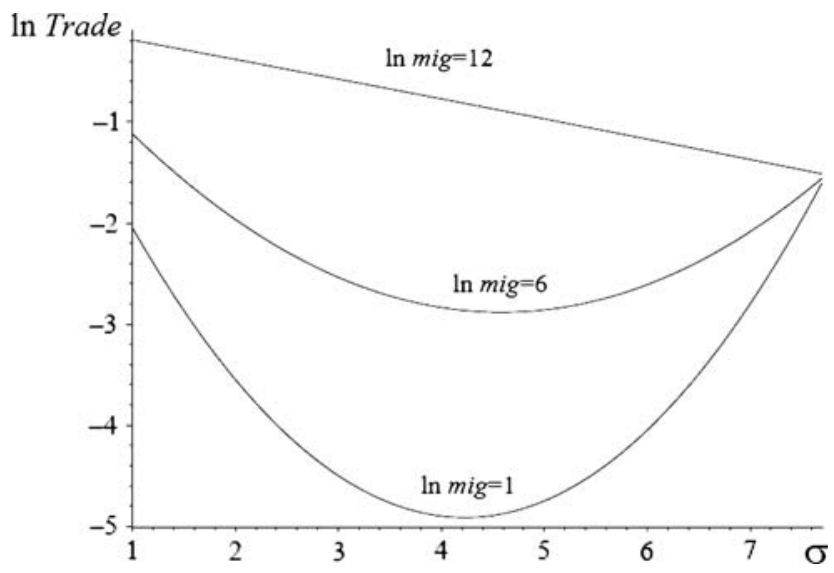

Fig. 3 The impact of $\sigma$ on trade

case, migration reduces the fixed export costs, allowing for the entry of new exporters. The explanation for this behaviour is that more differentiated products require more specialized transactions. For example, the supplier-buyer match is more complex for "optical instruments" (sector 871 with $\sigma=1.05$ ) than for "soap" (sector 554 with $\sigma=4.95$ ). Trade barriers will be harder to overcome for the former because of the need for highly specific knowledge about the market and transport. So, the more homogeneous a product, the simpler the trade barriers and the more easily an immigrant can overcome the trade barriers. At higher $\sigma$ values, the transactions become so straightforward that there is little leeway for migration effects. Rauch and Trindade (2002) defines homogeneous goods as being those traded on organized exchanges, which clearly incorporate much of the potential intermediation an immigrant could perform. The corresponding mechanism for the effects of migration on costs is the formation of networks, i.e. the relationship between immigrants and those who have remained in the country of origin, which could generate new exports.

However, it could be useful to analyze the direct effect of the elasticity of substitution on trade. This impact is expressed by ${ }^{18}$ :

$$
\begin{aligned}
\ln (\text { Trade })= & -2.325 \times \sigma+0.178 \times \ln (\text { Immig }) \times \sigma+0.275 \times \sigma^{2}-0.023 \\
& \times \ln (\text { Immig })) \times \sigma^{2}
\end{aligned}
$$

This function is plotted in Fig. 3. It predicts that, in the absence of migration, the effect is not monotonous: for low values of $\sigma$, trade is an increasing function of product differentiation, whereas for high values of $\sigma$, trade is a decreasing function of product differentiation. So highly differentiated products are traded more because of the exclusivity of their origins. Conversely, extremely homogeneous products can be easily substituted. Intermediate products are neither exclusive nor replaceable enough and are therefore traded less.

\footnotetext{
$\overline{18}$ Still considering the reference regression (3) in Table 4.
} 


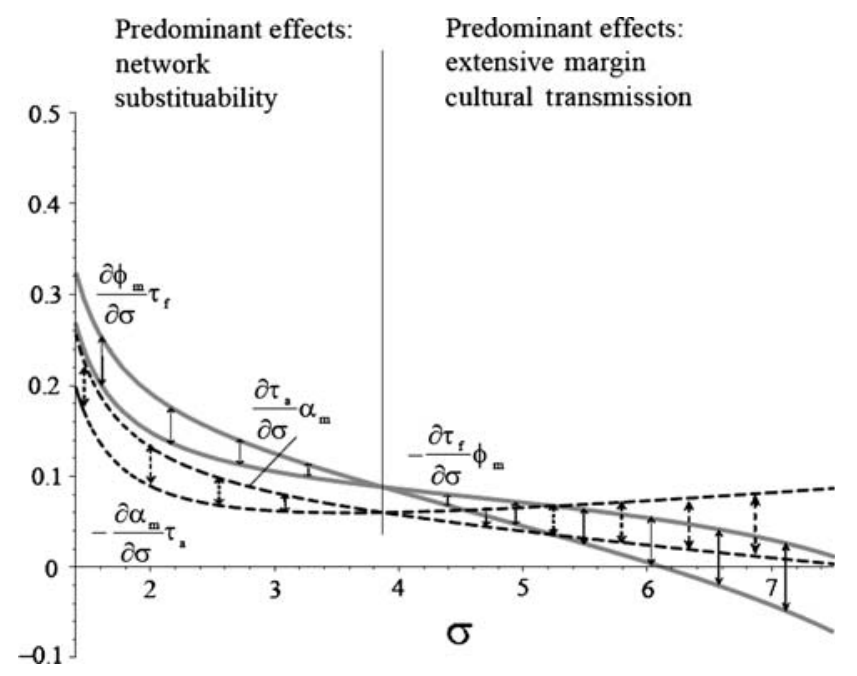

Fig. 4 Partial effects of migration, $\beta=0.5$

It is interesting to note that an increase in the number of migrants drives up the effect on trade until it eventually becomes linear and monotonous: where there are high numbers of migrants, trade is an increasing function of product differentiation for any $\sigma$.

\subsubsection{Defining the predominant effects of migration on trade}

Once these direct migration relationships have been clarified, we can define how complementary elasticities diverge. On the cost side, network and extensive margin have mostly opposite effects on trade as $\sigma$ increases. Figure 2 shows that the network effect is mostly an increasing function of $\sigma$ while the extensive margin effect is a decreasing function of $\sigma$. On the preferences side the substitutability effect is an increasing function of $\sigma$ while the cultural transmission effect is a decreasing effect of $\sigma$. Differentiating Eq. 13 on $\sigma$, we can determine predominating effects according to $\sigma$ :

$$
\frac{\partial F}{\partial \sigma}=\left(\frac{\partial \tau_{a}}{\partial \sigma} \alpha_{m}+\frac{\partial \alpha_{m}}{\partial \sigma} \tau_{a}\right)+\left(\frac{\partial \tau_{f}}{\partial \sigma} \varphi_{m}+\frac{\partial \varphi_{m}}{\partial \sigma} \tau_{f}\right)
$$

Each term $\frac{\partial \tau_{a}}{\partial \sigma} \alpha_{m}, \frac{\partial \alpha_{m}}{\partial \sigma} \tau_{a}, \frac{\partial \tau_{f}}{\partial \sigma} \varphi_{m}$ and $\frac{\partial \varphi_{m}}{\partial \sigma} \tau_{f}$ is presented in Fig. 4.

For the sectors with $\sigma>3.87^{19}$ the cultural transmission effect predominates the preference channel and the extensive margin effect predominates the cost channel. For the sectors with $\sigma<3.87$ the substitutability effect predominates the preference channel and the network effect predominates the cost channel. This means that, for an increase of $\sigma$, the proportional increase in "substitutability" will overcompensate

\footnotetext{
193.87 is the point maximizing the impact of migration on trade, determined by Eq. 21. It is where $\frac{\partial \tau_{a}}{\partial \sigma} \alpha_{m}=\frac{\partial \alpha_{m}}{\partial \sigma} \tau_{a}$ and $\frac{\partial \tau_{f}}{\partial \sigma} \varphi_{m}=\frac{\partial \varphi_{m}}{\partial \sigma} \tau_{f}$.
} 
the decrease in "preference transmission". This is roughly the case for Switzerland, with an average $\sigma=2.9$ for exports and $\sigma=3.4$ for imports, imports being more affected by migration because of the higher substitutability of their products, even though preferences for exported products are greater than those for imported products. This is a very surprising result. It demonstrates that cultural and information transmission have a much greater impact on defining preferences than the immigrant's individual consumption. Moreover, this transmission clearly moves in both directions, from home country to host country and from host country to home country. Conversely, the "network" effect in the cost channel overcompensates the "extensive margin". Whereas the "extensive margin" is beneficial to exports, the immigrant "network" effect has more of an impact on imports. In this case, the network effect predominates, raising imports more than exports.

\section{Conclusion}

This paper conducts an empirical study of the effects of migration on trade using a new approach that considers the market structure of exports and imports and inference mechanisms such as cultural and information transmission and network formation.

Swiss and French migration data are used along with sector-based trade data. The market structure is then studied in terms of these sectors' differentiation as shown by their elasticity of substitution. A suitable theoretical model taking into account sector heterogeneity based on Chaney (2008) predicts how preferences and costs vary as a sector's substitutability level varies.

The findings are in keeping with comparable studies insomuch as migration has a greater effect on imports than on exports. However, a multisector analysis interacting migration with the elasticity of substitution suggests that market structure determines to a large extent how migration affects trade. Migration is found to influence preferences more in differentiated products and impact costs in an inverted U-shape, being more intense in products with an elasticity of substitution close to 6 and less intense as this elasticity approaches 1 or 7.8 .

Switzerland's imports are more affected by migration than its exports. As regards the preference channel, this happens because Swiss imported goods are more substitutable and hence more easily affected by preferences. As regards the fixedcost channel, this happens because imported goods call for more straightforward trade transactions that immigrants are more able to intermediate. The residual effect of migration on preference enhances preferences for Swiss products because of its highly differentiated composition.

Acknowledgments Thanks are extended to Elisabeth Aebischer (Swiss Federal Statistics Office), Karin Schär (Swiss Federal Department of Foreign Affairs) and Bernard Gentil (French Ministry of Foreign and European Affairs) for kindly supplying data; professors Robert C. Feenstra and Robert E. Lipsey for their explanations regarding the trade data; professors Thierry Verdier, Lionel Fontagné and Thierry Mayer for their guidance; and Vincent Rebeyrol, Fabian Gouret, Julien Vauday, Lysu Paez, Rémi Bazillier, Gautier Duflos, José de Sousa and Vincent Vicard for their help and suggestions. The author is grateful to CIREM/CEPII for their financial support. 


\section{Appendix}

Table 5 Instrumental variable for immigrants in Switzerland

\begin{tabular}{lll}
\hline Specification & PPLM & \\
\cline { 2 - 3 } $\begin{array}{l}\text { Dependent variable } \\
\text { Model }\end{array}$ & $\begin{array}{l}\text { Exp } \\
(1)\end{array}$ & $\begin{array}{l}\text { Imp } \\
(2)\end{array}$ \\
\hline Intercept & $-6.81^{* * *}(2.40)$ & $-7.80 * * *(2.15)$ \\
ln partner GDP & $0.80 * * *(0.15)$ & $0.25(0.20)$ \\
ln partner Pop. & $0.01(0.73)$ & $1.20(1.09)$ \\
ln distance & $-0.71(1.54)$ & $-1.76(2.16)$ \\
Adjacency & $-2.29(8.53)$ & $-0.10(1.28)$ \\
Common language & $1.22(5.27)$ & $0.09(1.98)$ \\
ln immigrants in Switz. & $0.52^{*}(0.29)$ & $0.84 * *(0.39)$ \\
Observations & 878 & 801 \\
\hline
\end{tabular}

Note: Robust standard errors (country-pair clustered) in parentheses with *, ** and ***, respectively, denoting significance at the 1,5 and 10\% levels. Time and country dummies are included in all estimations. All models are estimated by PPML

\section{References}

Anderson, J. E., \& van Wincoop, E. (2003). Gravity with gravitas: A solution to the border puzzle. American Economic Review, 93(1), 170-192.

Bowles, S. (1998). Endogenous preferences: The cultural consequences of markets and other economic institutions. Journal of Economic Literature, 36(1), 75-111.

Broda, C., \& Weinstein, D. E. (2006). Globalization and the gains from variety. Journal of Political Economy, 99(4), 722-742.

Chaney, T. (2008). Distorted gravity: The intensive and extensive margins of international trade. American Economic Review, 98(4), 1707-1721.

Combes, P. P., Lafourcade, M., \& Mayer, T. (2005). The trade-creating effects of business and social networks: Evidence from France. Journal of International Economics, 66(1), 1-29.

Dunlevy, J. A., \& Hutchinson, W. K. (1999). The impact of immigration on American import trade in the late nineteenth and early twentieth century. Journal of Economic History, 59(4), 1043-1062.

Feenstra, R. C. (2004). Advanced international trade: Theory and evidence. Princeton: Princeton University Press.

Feenstra, R. C., Lipsey, R. E., Deng, H., Ma, A. C., Mo, H. (2005). World trade flows: 1962-2000. NBER Working Paper No. 11040. Cambridge: National Bureau of Economic Research.

Girma, S., \& Yu, Z. (2002). The link between immigration and trade: Evidence from the United Kingdom. Weltwirtschaftliches Archiv/Review of World Economics, 138(1), 115-130.

Gould, D. M. (1994). Immigrant links to the home country: Empirical implications for U.S. bilateral trade flows. Review of Economics and Statistics, 76(2), 302-316.

Head, K., \& Ries, J. (1998). Immigration and trade creation: Econometric evidence from Canada. Canadian Journal of Economics, 31(1), 47-62.

Krugman, P. R. (1980). Scale economies, product differentiation and the pattern of trade. American Economic Review, 70(5), 950-959. 
Melo, J., Miguet, F., \& Müller, T. (2002). The political economy of EU enlargement: Lessons from Switzerland. CEPR Discussion Paper No. 3449. London: Centre for Economic Policy Research.

Rauch, J. (2001). Business and social networks in international trade. Journal of Economic Literature, 39(4), 1177-1203.

Rauch, J., \& Trindade, V. (2002). Ethnic Chinese networks in international trade. Review of Economics and Statistics, 84(1), 116-130.

Santos Silva, J. M. C., \& Tenreyro, S. (2006). The log of gravity. Review of Economics and Statistics, $88(4), 641-658$.

Wagner, D., Head, K., \& Ries, J. (2002). Immigration and the trade of provinces. Scottish Journal of Political Economy, 49(5), 507-525.

White, H. (1980). A heteroskedasticity-consistent covariance matrix estimator and a direct test for heteroskedasticity. Econometrica, 48(4), 817-838. 